Neurosurg Focus 7 (6):Article 1, 1999

\title{
Efficacy of variable-angle screws in transpedicular fixation
}

\author{
Paul M. Arnold, M.D., Robert D. Strang, M.D., and Danielle Roussel, B.S. \\ Section of Neurosurgery, University of Kansas Medical School, Kansas City, Kansas
}

The purpose of this study was to evaluate the usefulness and efficacy of variable-angle screws in transpedicular fixation.

Sixteen patients (10 men and six women, age range $44--73$ years) underwent a posterior transpedicular fixation procedure in which variable-angle screws were placed at two or more levels. Four patients experienced spinal instability secondary to trauma, 10 patients suffered from degenerative spondylosis requiring fusion, and two patients were treated for spinal metastatic disease. All patients underwent posterior transverse process fusion in which autologous bone was used. In total, 37 vertebral levels were fixed with variable-angle screws placed at 22 levels. Postoperatively all patients were fitted with an external orthosis that was worn for 12 weeks. Serial postoperative plain x-ray films were obtained in all cases. Follow-up periods ranged from 11 to 24 months.

Based on clinical and radiographic data, solid fusion was achieved in 14 of 16 patients. There were two early disconnections of the rod/screw connectors, which were related to errors in technique. With the exception of these disconnections, there were no cases of construct failure. There were no wound infections, and no patient experienced a decline in neurological function as compared with preoperative levels. Both instrumentation systems were easy to use, and the flexibility in trajectory allowed for quicker screw placement and decreased operating room time.

Variable-angle pedicle screws are a safe, useful adjunct to transpedicular fixation, particularly in multisegment fixation and in spines with abnormal alignment.

Key Words * pedicle fixation * lumbar fusion * pedicle screw

Internal fixation of the thoracolumbar, lumbar, and lumbosacral spine is indicated for treatment of degenerative disease, as well as iatrogenic, traumatic, or metastatic instability.[2,4,6,10,15,16,18,21,22,25-28,32,35-37] Fixation involving fusion and placement of instrumentation has advantages over fusion in which instrumentation is not used. It provides immediate stability for postoperative mobilization, enhances the likelihood of fusion, corrects deformity, and preserves the sagittal profile.[6,15-17,21,22,28-30,35]

Compared with other fixation systems, segmental spinal purchase through transpedicular instrumentation 
provides the most biomechanically rigid restraint to spinal motion in flexion, extension, and torsion.[15,21,29,31,32,34-37] Because pedicle screw systems generally require fewer instrumented segments, they are advantageous in preserving motion segments, which is particularly important in the mobile lumbar spine. Transpedicular fixation has also been shown to increase fusion rates.[6,14,15,21,28,36,37] These advantages have made transpedicular fixation a mainstay of treatment for thoracolumbar and lumbar fusion procedures.

Despite advantages over other fixation techniques, transpedicular fixation is associated with risks of screw breakage; screw/rod disconnection; pseudarthrosis; and nerve root injury, dural laceration, and pedicle fracture during screw insertion. $[9,11,29,33,34]$ In situations in which long constructs are required, the screw and rod connections may become difficult to make due to discrepancies in the angles of the pedicles. Such conditions require contouring of the rod, which increases operative time and may lead to hardware failure secondary to the stress placed on the construct.

Variable-angle pedicle screws have been developed to overcome some of the limitations of standard (fixed-angle) screws. In particular, variable-angle screws are intended to allow achievement of better axis along the pedicle, minimize the need for contouring of the rod, decrease operative time, and make the process of placing the rod easier where adjacent fixed-angle screws are at acute angles, specifically the L5--S1 junction (Figs. 1 and 2).

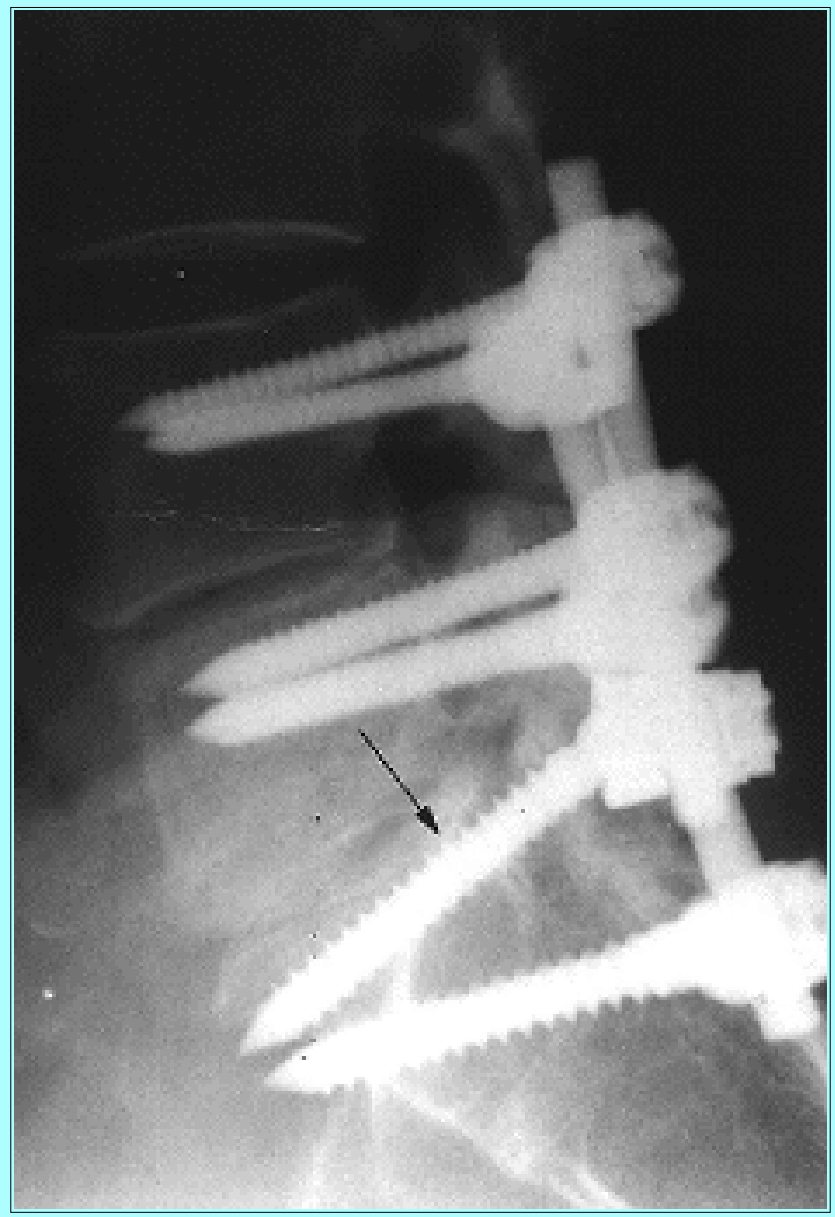

Fig. 1. Case 5. Lateral x-ray film demonstrating the presence of a variable-angle and a fixed-angle screw in the sacrum. The variable-angle screw (arrow) is parallel to the endplate. 


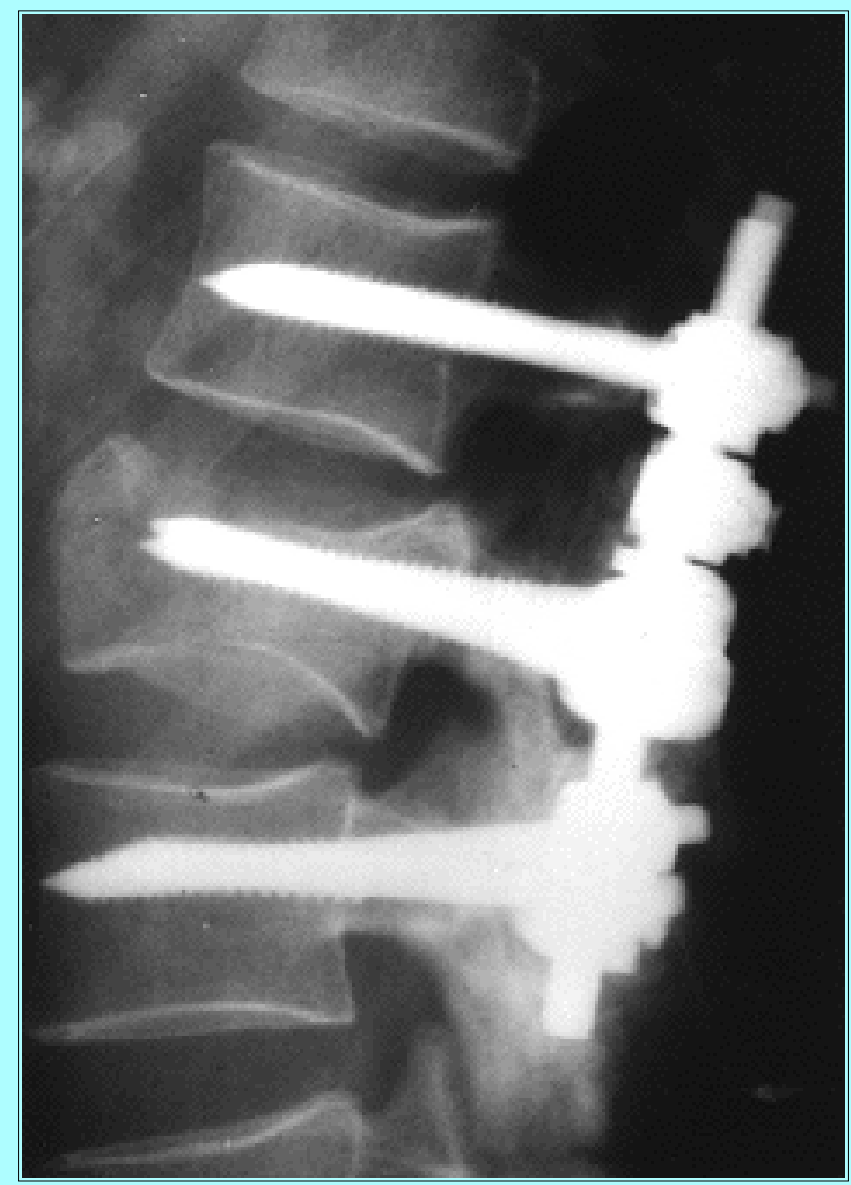

Fig. 2. Lateral x-ray film obtained of a thoracolumbar fracture. The variable-angle screws are shown in the fracture.

Although the precise optimum stiffness and bending strength for successful fusion is not clear, fixation devices should be rigid enough to prevent deformity and promote arthrodesis. Because the variable-angle screws possess angular mobility at the rod/screw connection, some surgeons question the device's ability to provide sufficient rigidity at the fixation site. According to the manufacturer (Synthes Spine, Paoli, PA) on static and dynamic testing, variable-angle screws were shown to have equivalent bending strength $(8.4 \mathrm{Nm})$ to that of the transverse bar construct and to perform to industry standards of 6 million cycles at $200 \mathrm{~N}$ in fatigue testing.

In this report we evaluate the clinical efficacy and safety of variable-angle screws in promoting arthrodesis in the thoracolumbar and lumbar spine.

\section{CLINICAL MATERIAL AND METHODS}

Between January 1, 1996 and June 30, 1998, 16 patients (10 men, six women, age 32-79 years) underwent transpedicular fixation in which variable-angle screws were used. Thirty-seven vertebral levels were fused with variable-angle screws used at 22 levels. Four patients experienced traumatic instability, 10 patients had degenerative spondylosis or spondylolisthesis requiring fusion, and two patients had metastatic disease (Tables 1 and 2). 
TABLE 1

CHARACTERISTICS OF 10 PATIENTS WITH DEGENERATIVE LUMBAR DISEASE WHO UNDERWENT TRANSPEDICULAR FIXATION WITH YAR MBLE-ANGLE SCREW SVSTEMS

\begin{tabular}{|c|c|c|c|c|c|c|c|}
\hline $\begin{array}{l}\text { Case } \\
\text { No. }\end{array}$ & Diagnosis & $\begin{array}{c}\text { Age (yrs), } \\
\text { Sex }\end{array}$ & $\begin{array}{l}\text { Levels } \\
\text { Irstru- } \\
\text { merted }\end{array}$ & $\begin{array}{l}\text { Pain } \\
\text { Recuc- } \\
\text { tion }\end{array}$ & $\begin{array}{l}\text { Follow } \\
U_{p} \\
(m \infty s)\end{array}$ & $\begin{array}{l}\text { Postop } \\
\text { Change }\end{array}$ & Complications \\
\hline 1 & $\begin{array}{l}\text { degenerative } \\
\text { spondylosis }\end{array}$ & $64, M$ & $\mathrm{~L} 3-\mathrm{S1}$ & yes & 26 & $\begin{array}{l}\text { increased } \\
\text { activity }\end{array}$ & $\begin{array}{l}\text { disconnection of } \\
\text { scewtod con- } \\
\text { nector on } 1 \\
\text { side, followed; } \\
\text { fusion at } 12\end{array}$ \\
\hline 2 & $\begin{array}{l}\text { degenerative } \\
\text { spondylosis }\end{array}$ & $69, M$ & $L 4-S 1$ & minimal & 24 & none & $\begin{array}{l}\text { mos } \\
\text { disconnection of } \\
\text { screwitod con- } \\
\text { nector on } 1 \\
\text { side; reop; } \\
\text { fusion }\end{array}$ \\
\hline 3 & $\begin{array}{l}\text { degenerative } \\
\text { spondylosis }\end{array}$ & $73, \mathrm{~F}$ & $L 4-81$ & yes & 22 & $\begin{array}{l}\text { increased } \\
\text { activity }\end{array}$ & none \\
\hline 4 & $\begin{array}{l}\text { degenerative } \\
\text { spondylosis }\end{array}$ & $68, F$ & $L 4-81$ & yes & 21 & $\begin{array}{l}\text { increased } \\
\text { activity }\end{array}$ & none \\
\hline 5 & $\begin{array}{l}\text { Grade I spondy- } \\
\text { lolis thesis }\end{array}$ & $59, M$ & L5- S1 & yes & 24 & $\begin{array}{l}\text { increased } \\
\text { activity }\end{array}$ & none \\
\hline 6 & $\begin{array}{l}\text { degenerative } \\
\text { spondylosis }\end{array}$ & $64, F$ & $L 4-S 1$ & no & 24 & none & none \\
\hline 7 & $\begin{array}{l}\text { degenerative } \\
\text { spondylosis }\end{array}$ & $61, F$ & L3-5 & yes & 20 & $\begin{array}{l}\text { increased } \\
\text { activity }\end{array}$ & none \\
\hline 8 & $\begin{array}{l}\text { degenerative } \\
\text { spondylosis }\end{array}$ & $60, M$ & L3-S1 & yes & 24 & $\begin{array}{l}\text { increased } \\
\text { activity }\end{array}$ & none \\
\hline 9 & $\begin{array}{l}\text { degenerative } \\
\text { spondylosis }\end{array}$ & $62, M$ & $L 4-81$ & yes & 18 & $\begin{array}{l}\text { increased } \\
\text { activity }\end{array}$ & none \\
\hline 10 & $\begin{array}{l}\text { degenerative } \\
\text { spondylosis }\end{array}$ & $63, F$ & $L 4-S 1$ & yes & 16 & $\begin{array}{l}\text { increased } \\
\text { activity }\end{array}$ & none \\
\hline
\end{tabular}

\section{TABLE 2}

CHARACTERISTICS IN SIX PATIENTS WITH TRAUMA-RELATED INSTABLITY AND SPINE METASTASES WHO UNDERWENT TRANSPEDICULAR FIXATION WITH YAR MBLE-ANGLE SCREW SVSTEMS

\begin{tabular}{|c|c|c|c|c|c|c|c|c|}
\hline $\begin{array}{l}\text { Case } \\
\text { No. }\end{array}$ & Diagnosis & $\begin{array}{c}\text { Age (ys), } \\
\text { Sex }\end{array}$ & $\begin{array}{l}\text { Levels } \\
\text { Irstru- } \\
\text { mented }\end{array}$ & $\begin{array}{c}\text { Pain } \\
\text { Re- } \\
\text { duced }\end{array}$ & $\begin{array}{c}\text { Follow } \\
U_{p} \\
(m \infty)\end{array}$ & $\begin{array}{l}\text { Postop } \\
\text { Changes }\end{array}$ & $\begin{array}{l}\text { Compli- } \\
\text { cations }\end{array}$ & $\begin{array}{l}\text { Loss of } \\
\text { Cor- } \\
\text { rection }\end{array}$ \\
\hline 1 & L-1 fracture & $47, M$ & T12-L2 & yes & 12 & back to work & none & $9^{\circ}$ \\
\hline 2 & $\begin{array}{l}\text { colon cancer metas- } \\
\text { tasis to } T-12\end{array}$ & $79, \mathrm{M}$ & T9-L2 & yes & 13 & $\begin{array}{l}\text { im pro ved am bu- } \\
\text { lation }\end{array}$ & none & $10^{\circ}$ \\
\hline 3 & L-2 fracture & 44, M & L1-3 & yes & 16 & back to work & none & $7^{\circ}$ \\
\hline 4 & $\begin{array}{l}\text { metastasis to L-3 } \\
\text { unknown primary }\end{array}$ & $55, M$ & L1-4 & yes & 11 & increased activity & none & $6^{\circ}$ \\
\hline 5 & L- 1 fracture & $32, F$ & T12-L2 & yes & 12 & back to work & none & $8^{\circ}$ \\
\hline 6 & T-12 fracture & $38, M$ & $\mathrm{~T} 11-\mathrm{L} 1$ & yes & 12 & none & none & $11^{\circ}$ \\
\hline
\end{tabular}

Four of the patients were cigarette smokers, and two patients had undergone previous surgery. Medical history was obtained in each case, and all patients underwent a physical examination as well as appropriate radiological examination, which consisted of plain anteroposterior and lateral radiography and either magnetic resonance imaging or computerized tomography myelography. Flexion--extension radiographs were also obtained in some patients. 
After informed consent was obtained, each patient underwent a standard posterior approach to the thoracic or lumbar spine. Patients were placed prone on the operating table, and a subperiosteal dissection of the facets, lamina, and transverse processes at the appropriate levels was performed. Intraoperative radiography was used to confirm the correct level.

The posterior elements were decorticated using a high-speed drill, and cancellous bone from the iliac crest was harvested for the fusion. The autograft was augmented with bone obtained from a laminectomy when decompression was indicated. The pedicles were identified with an awl and confirmed with the use of a pedicle probe and intraoperative fluoroscopy. Following placement of the pedicle screws, screw/rod connectors were used to connect the screws with the rod. It was necessary to contour the rod in five cases. If necessary, distraction, compression, or restoration of lordosis was used to correct the spinal deformity. Transverse connectors were used in cases of trauma and metastatic instability. Bone was placed over the transverse processes, the facets were packed, and the wound was closed in layers. All patients received intravenous antibiotics at the time of incision, and a cell saver was used in all cases except for those with suspected metastatic disease.

All patients were mobilized as soon as possible. Each patient wore an external orthosis for 8 to 12 weeks. Serial postoperative radiographs were obtained at follow-up clinic visits at 2 weeks, 6 weeks, 3 months, 6 months, 1 year, and 2 years (Figs. 1 and 2).

The variable-axis screws (Synthes Spine), a side-loading system, consist of a titanium nut, collar, locking ring, and a screw/rod connector. The screws are 5,6, and $7 \mathrm{~mm}$ in diameter and 40 to $60 \mathrm{~cm}$ in length.[30] The screw/rod connector was initially separate from the screw, and because of this, disconnection occurred in two of our patients. The rod/screw connector allows $72^{\circ}$ of angulation in any plane. The polyaxial pedicle screws consist of the pedicle screw with an attached three-dimensional head and locking cap. These screws allow $25^{\circ}$ of angulation in all directions. The screws are placed through the pedicle into the body with the screw parallel to the endplate. The locking rings are impacted in place, and the rod is then inserted into the screw/rod connectors, which can pivot about the head of the screw. The collars are then placed over the rod and the nuts tightened over the collar[1] (Fig. 3).

Fig. 3. Photograph of the Synthes variable-angle screw (the second generation screw) demonstrating the screw/rod connector attached to the screw (curved arrow), the nut 
(arrowhead), collar (open arrow), and locking nut (arrow). Lower: Photograph showing the Synthes variable-angle screw connected to a rod.

The Multi Axial Screw System (Sofamor Danek, Memphis, TN) is similar to the Synthes screw, although it is a top-loading system. The screw consists of three components that are delivered preassembled: a head, crown, and bone screw. The screw allows $25^{\circ}$ of angulation in any plane. Once the screws are placed into the pedicles, the rod is inserted into the top of the "tulip" portion of the head. After the rod is seated in the head, a set screw is threaded into the top of the "tulip" over the rod (Fig. 4).

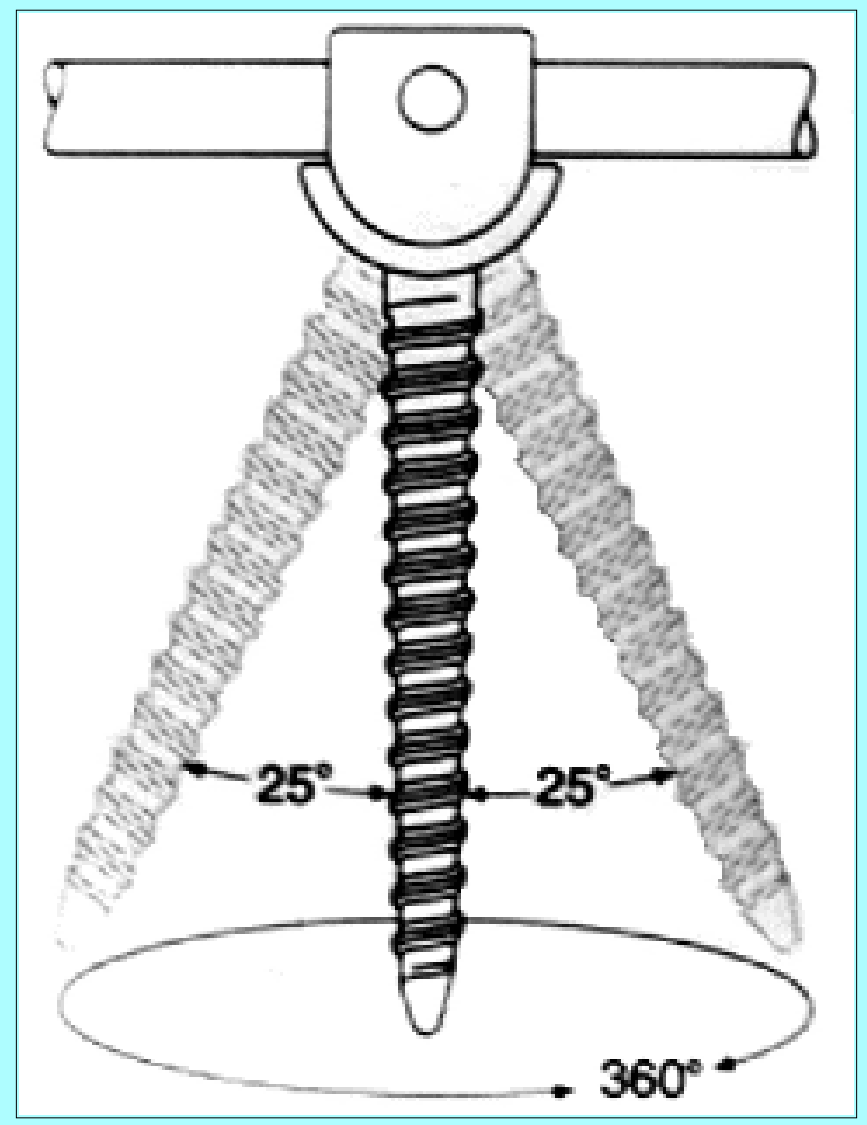

Fig. 4. Diagram showing the Sofamor Danek variable-angle screw.

\section{RESULTS}

All patients underwent follow up for a minimum of 1 year, except for one patient with metastatic disease who was lost to follow up at 11 months. Successful fusion was determined by evaluating anteroposterior $\mathrm{x}$-ray films for the presence of bridging bone between the transverse processes and trabeculae through the fusion mass.[5,7,12,19,36] Flexion--extension radiographs were used to detect the presence/absence of movement. Postoperative x-ray films were reviewed to determine if there was loss of deformity correction following surgery for trauma-related instability or metastatic disease. In 14 of 16 patients solid fusions were present at 1-year follow up. The only exceptions were the two patients with metastatic disease, both of whom underwent radiotherapy following surgery. However, these two patients experienced the most dramatic pain relief, and one of them regained the ability to ambulate following surgery.[2,18] Three of the four patients with thoracolumbar fractures experienced reduced pain following surgery and returned to work.[4,24,25,32] Eight of 10 patients with degenerative lumbar disease reported reduced pain and an increase in their activities of daily living.[26,27]

Postoperative x-ray films, operating room records, and charts of comparable patients undergoing pedicle 
fixation were reviewed. Loss of correction and the operative time necessary to complete the fixation procedure were assessed. In the group of patients with degenerative lumbar disease (10 patients, Table 1), because preoperative kyphosis was not present, there was no loss of correction. In the one patient with Taillard Grade 1 isthmic spondylolisthesis (Case 5; Table 1) no progression of vertebral body slippage was demonstrated following surgery. Placement of hardware (pedical screw insertion, rod contouring, $\mathrm{rod} / \mathrm{screw}$ connection, and intraoperative radiography) in this study took an average of 36.3 minutes for placement of two-level constructs and 48.6 minutes for three-level constructs. These values compare with 42.4 minutes and 60.1 minutes for the placement of two-level and three-level constructs, respectively, in comparable patients undergoing standard pedicle screw constructs. This resulted in a savings of approximately 6 minutes per level of operative time.

In patients with trauma-related injury or metastatic disease--related instability (Table 2), there was an average loss at 1 year of $8.5^{\circ}$ following initial correction. This value compares favorably with that obtained in several previous studies, [27,30] as well as our own findings (PM Arnold, DL Kirschman, unpublished data). Insertion of the two-level construct in cases of trauma-related instability took somewhat longer than that for patients with degenerative lumbar disease: 40.6 compared with 36.3 minutes, respectively. This additional time was used for distraction of the fracture, restoration of lordosis, and placement of transverse connectors.

There were two surgery-related complications, both involving early disconnection of the screw/rod connectors at one level of the construct. This was attributed to difficulties in properly seating the screw/rod connector on the head of the screw. One patient required reoperation to correct this; the second patient wished to have the complication monitored at follow-up visits. Fusion was achieved in both patients at 12-month follow up. This problem (in the Synthes screw) has been resolved, and the screw/rod connector is now affixed to the screw. There were no other construct failures. There were no wound infections, and no patient experienced a decline in neurological function as compared with preoperative levels.

\section{DISCUSSION}

Except in those with metastatic disease, solid fusion was achieved in all of our patients. Variable-angle screw constructs have been shown to have similar fusion success rates compared with fixed-axis screw devices (up to $95 \%$ in some series).[3,4,6-8,10,14-16,22,26,28,29,31,35-37] Although radiographic evaluation is known to be of low sensitivity in the detection of arthodesis and to have a 30 to $40 \%$ correlation compared with surgical exploration, this method of evaluation is similar to those used to determine fusion in other series.[3,5,7,19] Fusion success is influenced by bone density, ligamentous integrity, muscle quality and strength, use of autograft or allograft, and the amount of bone available for fusion. $[3,6,8,14]$ Risk factors for pseudarthrosis include smoking, osteoporosis, obesity, a history of previous fusion failure, and use of allograft bone or bone substitute.[3,8,20,23] The characteristics of the patients in this study are comparable with the mix of patient characteristics in other studies. $[4,6,15,16,28]$

The $0 \%$ infection rate in this study is a favorable factor compared with other reported infection rates in patients undergoing fusion in which instrumentation is used. This is attributed to the use of prophylactic antibiotic medication, minimal number of people in the operating room, sterile operating technique, the relative good health of the patients in the series, and possibly the more efficient placement of hardware because of the use of variable-angle screws. Seven patients had predisposing risk factors (metastatic disease, smoking, and previous surgery).[8] Both patients with metastatic disease were undergoing their 
first spinal procedure, did not have widely metastatic spread, and did not undergo radiotherapy until their wounds were completely healed.[2,18]

The complications in this study occurred early in our experience and were due to errors in surgical technique. In both instances, the Synthes screw/rod connector became disengaged from the screw, thus leaving the screw alone in the pedicle and no longer connected to the rod.[1] This complication usually leads to pseudarthrosis and the need for reoperation, which was necessary in one of our patients. The second patient in whom this occurred opted to undergo nonsurgical management, and fortunately fusion was subsequently shown in this patient. Screw/rod failure is more likely to be a problem in shorter-length constructs, particularly if it is at the caudad or cephalad end. This problem has been overcome by fitting the screw/rod connector to the head of the screw.

The variable-angle screws are most useful in multilevel constructs in which several screw/rod connections are necessary. In this regard, there is a greater "margin of safety" in both the mediolateral and sagittal dimensions. The need for rod contouring is lessened, and each screw may be placed on an axis parallel to the superior endplate, allowing maximal purchase and reducing the chance of neurological injury.[12,13,24] Although no hard data exist, we are convinced that the use of variable-angle screws shortens operative time, places less fatigue on the rod (because less contouring is required), and therefore may reduce infection rates and prevent early instrument failure.

Variable-angle screws are also useful in the sacrum, particularly in conjunction with fixation of L-5. The acute angle between screws at L-5 and S-1 makes rod placement difficult without a generous bend in the rod. This can be minimized or eliminated with variable-angle screws without sacrificing optimum screw placement (Fig. 1). Both instrumentation systems were easy to use in this regard, and the flexibility in trajectory allowed for the placement of the construct to be completed more quickly.

\section{CONCLUSIONS}

The use of variable-angle screws in transpedicular fixation allows for increased flexibility in screw placement technique. This feature minimizes the need for rod contouring, avoids prestressing the construct, and decreases operating room time by approximately 6 minutes per level. Loss of correction following thoracolumbar fractures is comparable with that in patients undergoing fixation with standard pedicle screws. The difficulties we encountered with the rod/screw connector seating have been eliminated with the system's new design. We conclude that variable-angle screws are a useful adjunct to transpedicular fixation, particularly in multisegment fixation and in spines with abnormal curvature or alignment.

\section{References}

1. Aebi M, Thalgott JS, Webb JK: Modular stabilization system: the universal spine system, in Aebi M, Thalgott JS, Webb JK (eds): AO ASIF Principles in Spine Surgery. Berlin:Springer-Verlag, 1998, pp $123-196$

2. Akeyson EW, McCutcheon IE: Single-stage posterior vertebrectomy and replacement combined with posterior instrumentation for spinal metastasis. J Neurosurg 85:211-220, 1996

3. An HS, Lynch K, Toth J: Prospective comparison of autograft vs. allograft for adult posterolateral lumbar spine fusion: differences among freeze-dried, frozen, and mixed grafts. J Spinal Disord 
4. Benzel EC, Kesterson L, Marchand EP: Texas Scottish Rite Hospital rod instrumentation for thoracic and lumbar spine trauma. J Neurosurg 75:382-387, 1991

5. Blumenthal SL, Gill K: Can lumbar spine radiographs accurately determine fusion in postoperative patients? Correlation of routine radiographs with a second surgical look at lumbar fusions. Spine 18:1186-1189, 1993

6. Bridwell KM, Sedgewick TA, O'Brien MF, et al: The role of fusion and instrumentation in the treatment of degenerative spondylolisthesis with spinal stenosis. J Spinal Disord 6:461-472, 1993

7. Brodsky AE, Kovalsky ES, Khalil MA: Correlation of radiologic assessment of lumbar spine fusions with surgical exploration. Spine 16 (Suppl 6):S261-S265, 1991

8. Brown CW, Orme TJ, Richardson HD: The rate of pseudarthrosis (surgical nonunion) in patients who are smokers and patients who are nonsmokers: a comparison study. Spine 11:942-943, 1986

9. Davne SH, Myers DL: Complications of lumbar spinal fusion with transpedicular instrumentation. Spine 17 (Suppl 6):S184-S189, 1992

10. Dickman CA, Fessler RG, MacMillan M, et al: Transpedicular screw-rod fixation of the lumbar spine: operative technique and outcome in 104 cases. J Neurosurg 77:860- 870, 1992

11. Esses SI, Sachs BL, Dreyzin V: Complications associated with the technique of pedicle screw fixation. A selected survey of ABS members. Spine 18:2231-2239, 1993

12. Farber GL, Place HM, Mazur RA, et al: Accuracy of pedicle screw placement in lumbar fusions by plain radiographs and computed tomography. Spine 20:1494-1499, 1995

13. Gertzbein SD, Robbins SEI: Accuracy of pedicular screw placement in vivo. Spine 15:11-14, 1990

14. Glassman SD, Dimar JR, Puno RM, et al: Salvage of instrumented lumbar fusions complicated by surgical wound infection. Spine 21:2163-2169, 1996

15. Grubb SA, Lipscomb MJ: Results of lumbosacral fusion for degenerative disc disease with or without instrumentation: two- to five-year follow-up. Spine 17:349-355, 1992

16. Herkowitz HN, Kurz LT: Degenerative lumbar spondylolisthesis with spinal stenosis: a prospective study comparing decompression with decompression and intertransverse process arthrodesis. J Bone Joint Surg (Am) 73:802-808, 1991

17. Hu SS, Pashman RS: Spinal instrumentation. Evolution and state of the art. Invest Radiol 27:632-647, 1992

18. Jonsson B, Sjostrom L, Olerud C, et al: Outcome after limited posterior surgery for thoracic and lumbar spine metastases. Eur Spine J 5:36-44, 1996

19. Kant AP, Daum WJ, Dean SM, et al: Evaluation of lumbar spine fusion. Plain radiographs versus direct surgical exploration and observation. Spine 20:2313-2317, 1995

20. Kumano K, Hirabayashi S, Ogawa Y, et al: Pedicle screws and bone mineral density. Spine 
19:1157-1161, 1994

21. Mardjetko SM, Connolly PJ, Shott S: Degenerative lumbar spondylolisthesis. A meta-analysis of literature 1970-1973. Spine 19 (Suppl 20):2256S-2265S, 1994

22. Masferrer R, Gomez CH, Karahalios DG, et al: Efficacy of pedicle screw fixation in the treatment of spinal instability and failed back surgery: a 5-year review. J Neurosurg 89:371-377, 1998

23. McAfee PC, Farey ID, Sutterlin CE, et al: Device-related osteoporosis with spinal instrumentation. Spine 14:919-926, 1989

24. McCormack BM, Benzel EC, Adams MS, et al: Anatomy of the thoracic pedicle. Neurosurgery 37:303-308, 1995

25. Olerud S, Kallstrom G, Sjostrom L: Transpedicular fixation of thoracolumbar vertebral fractures. Clin Orthop 227:44-51, 1988

26. Ricciardi JE, Pflueger PC, Isaza JE, et al: Transpedicular fixation for the treatment of isthmic spondylolisthesis in adults. Spine 20:1917-1922, 1995

27. Sasso RC, Cotter HB, Reuben JD: Posterior fixation of thoracic and lumbar spine fractures using DC plates and pedicle screws. Spine 16 (Suppl 3):S134-S139, 1991

28. Schnee CL, Freese A, Ansell LV: Outcome analysis for adults with spondylolisthesis treated with posterolateral fusion and transpedicular screw fixation. J Neurosurg 86:56-63, 1997

29. Schwab FJ, Nazarian DG, Mahmud F, et al: Effects of spinal instrumentation on fusion of the lumbosacral spine. Spine 20:1917-1922, 1995

30. Sim E, Stergar PM: The Fixateur Interne for stabilising fractures of the thoracolumbar and lumbar spine. Int Orthop 16:322-329, 1992

31. Steffee AD, Brantigan JW: The variable screw placement spinal fixation system. Report of a prospective study of 250 patients enrolled in Food and Drug Administration clinical trials. Spine 18:1160-1172, 1993

32. Vornanen MJ, Bostman OM, Myllynen PJ: Reduction of bone retropulsed into the spinal canal in thoracolumbar vertebral body compression burst fractures. A prospective randomized study between Harrington rods and two transpedicular devices. Spine 20:1699-1703, 1995

33. West JL III, Ogilvie JW, Bradford DS: Complications of the variable screw plate pedicle screw fixation. Spine 16:576-579, 1991

34. Yahiro MA: Comprehensive literature review. Pedicle screw fixation devices. Spine 19 (Suppl 20):2274S-2278S, 1994

35. Yuan HA, Garfin SR, Dickman CA, et al: A historical cohort study of pedicle screw fixation in thoracic, lumbar, and sacral spinal fusions. Spine 19 (Suppl 20):2279S-2296S, 1994

36. Zdeblick TA: A prospective randomized study of lumbar fusion. Preliminary results. Spine 18:983-991, 1993 
37. Zindrick MR: The role of transpedicular fixation systems for the stabilization of the lumbar spine. Orthop Clin North Am 22:333-344, 1991

Manuscript received October 1, 1999.

Accepted in final form December 6, 1999.

Address reprint requests to: Paul M. Arnold, M.D., Section of Neurosurgery, University of Kansas, 3901 Rainbow Boulevard, Kansas City, Kansas 66160. 